\title{
Performance Assessment and Comparison of Two Piezoelectric Energy Harvesters Developed for Pavement Application: Case Study
}

\author{
Chenchen Li ${ }^{1,2}{ }^{\mathbb{D}}$, Shifu Liu ${ }^{1}$, Hongduo Zhao ${ }^{1, * \mathbb{D}}$ and Yu Tian ${ }^{1, * \mathbb{D}}$ \\ 1 The Key Laboratory of Road and Traffic Engineering, Ministry of Education, Tongji University, \\ Shanghai 201804, China; lichenchen@tongji.edu.cn (C.L.); sfliu_tongji@163.com (S.L.) \\ 2 Institute of Highway Engineering, RWTH Aachen University, 52074 Aachen, Germany \\ * Correspondence: hdzhao@tongji.edu.cn (H.Z.); dr.yutian@tongji.edu.cn (Y.T.)
}

Citation: Li, C.; Liu, S.; Zhao, H.; Tian, Y. Performance Assessment and Comparison of Two Piezoelectric Energy Harvesters Developed for Pavement Application: Case Study. Sustainability 2022, 14, 863. https:// doi.org/10.3390/su14020863

Academic Editors: Young-Ji Byon,

Feng Chen and Meng Guo

Received: 12 December 2021

Accepted: 6 January 2022

Published: 13 January 2022

Publisher's Note: MDPI stays neutral with regard to jurisdictional claims in published maps and institutional affiliations.

Copyright: (C) 2022 by the authors. Licensee MDPI, Basel, Switzerland. This article is an open access article distributed under the terms and conditions of the Creative Commons Attribution (CC BY) license (https:// creativecommons.org/licenses/by/ $4.0 /)$.

\begin{abstract}
To advance the development of piezoelectric energy harvesters, this study designed and manufactured bridge-unit-based and pile-unit-based piezoelectric devices. An indoor material testing system and accelerated pavement test equipment were used to test the electrical performance, mechanical performance, and electromechanical coupling performance of the devices. The results showed that the elastic modulus of the pile structure device was relatively higher than that of the bridge structure device. However, the elastic modulus of the two devices should be improved to avoid attenuation in the service performance and fatigue life caused by the stiffness difference. Furthermore, the electromechanical conversion coefficients of the two devices were smaller than $10 \%$ and insensitive to the load magnitude and load frequency. Moreover, the two devices can harvest $3.4 \mathrm{~mW}$ and $2.6 \mathrm{~mW}$ under the wheel load simulated by the one-third scale model mobile load simulator, thus meeting the supply requirements of low-power sensors. The elastic modulus, electromechanical conversion coefficients, and electric performance of the pile structure device were more reliable than those of the bridge structure device, indicating a better application prospect in road engineering.
\end{abstract}

Keywords: road engineering; energy harvesting; piezoelectric device; electrical performance; mechanical performance; electromechanical coupling performance

\section{Introduction}

With increasingly prominent environmental problems and energy shortages, the transportation system has become a critical area of energy saving and emission reduction. Renewable energy and energy harvesting technologies have received unprecedented attention [1]. Researchers have given extensive attention to energy harvesting and utilization technologies, such as photovoltaic, wind energy, piezoelectric, thermoelectric, and triboelectric for roadway applications [2-5]. In addition, with the rapid development of intelligent connected vehicles, autonomous vehicles, and intelligent transportation systems, traditional roads are required to be functional and intelligent to satisfy new requirements [6-8]. Pavements are subjected to more than millions of vehicles loads, thus generating remarkable mechanical energy during their service life. Based on the positive piezoelectric effect of piezoelectric materials $[9,10]$, piezoelectric energy harvesters (PEHs) can convert this kinetic energy into electrical energy (5). The developed PEHs can be utilized to power low-power sensors for traffic flow monitoring [11], structural health monitoring [8], and vehicle weight estimation [12], as well as to power electronics, such as signals, lights, and Internet of things systems $[13,14]$. Furthermore, research indicates that PEH technology has technical advantages, such as a low environmental impact, high energy density, and around-the-clock service, and could be the leading technology in green and intelligent roads [15]. 
Many pioneer studies have addressed the development and manufacture of PEHs. Innowattech Ltd. proposed an energy harvesting system based on piezoelectric generators to harvest electricity from road traffic [16]. Zhao began research on PEHs in China through finite element analysis and investigated the energy conversion efficiency of cymbal and bridge transducers [17]. The study indicated that the output power of a cymbal can reach $1.20 \mathrm{~mW}$ with a load of $0.7 \mathrm{MPa}$ and $20 \mathrm{~Hz}$ [18]. To improve the energy generation efficiency and increase the durability of the transducers, researchers have successively proposed and optimized various transducers, such as a layered bridge [19], low-frequency cymbal [20], stacked [21], and both-ends-fixed beam [22] transducers. In addition, Wang used laboratory experiments to optimize the process of stacked piezoelectric units and evaluated their application performance in terms of electromechanical conversion performance and structural strength $[23,24]$. Yang conducted compressive testing and electrical fatigue testing of piezoelectric devices and investigated the influences of load magnitude, frequency, and temperature on the electrical performance of stacked unit-based piezoelectric devices [25,26]. Zhao used numerical simulation methods to analyze the influence of pavement-embedding parameters and pavement structures on the electrical and mechanical properties of bridge piezoelectric transducers [27]. Cao analyzed variations of the electrical properties of piezoelectric devices from the three aspects of load magnitude, load speed, and resistance $[28,29]$. Tong and Wang analyzed the influence of structure parameters on the power generation of piezoelectric cantilever beams and proposed a parameter optimization method [30,31]. Roshani conducted experimental tests and finite element analyses on three piezoelectric transducer structures and studied the stress transfer and electromechanical conversion efficiency of these piezoelectric structures [32]. In addition, Liu and Zhao conducted research on the synergistic performance between devices and pavement [27,33]. Yang performed demonstration projects to test the field performance of a piezoelectric device, and the generated electrical energy successfully lit a roadside sign [34]. Wang tested the electrical performance of a road PEH system based on field tests and verified the effectiveness of the system's energy collection and storage [35]. In summary, researchers have conducted comprehensive studies on material development and structural design and optimization. They have also performed compatibility performance analyses, interface circuit development via theoretical analyses, numerical simulation analyses, and indoor and field experiments. These studies have established the foundation for pavement application of PEHs.

Due to the cost- and time-intensive nature of developing piezoelectric devices, a material testing system (MTS), wheel-tracking device, and accelerated pavement testing (APT) device have been used to evaluate the performance of different piezoelectric devices. Yang used a servo press and small accelerated loading test equipment to evaluate the structural strength and electrical fatigue of stacked piezoelectric devices [26]. Wang constructed simulation systems to test the electricity-generating performance of small piezoelectric stack units [24]. Li used an MTS and a wheel rutting tester to investigate the structural strength and electrical performance of a piezoelectric unit $[11,21]$. However, no unified testing and evaluation methods have been summarized for the mechanical and electrical performance. Furthermore, the difficulty of comparing the energy conversion efficiency and structural performance given by the existing research limits the development of PEH technology.

This work described a multiscale test method to investigate the performances of piezoelectric devices. The bridge-unit-based and pile-unit-based piezoelectric devices were designed and manufactured in this case study. Moreover, the electrical performance, mechanical performance, and electromechanical coupling performance of the two piezoelectric devices were investigated and compared. The research provides effective testing and evaluation methods for road energy harvesting. 


\section{Structures and Methods}

\subsection{Structures}

According to piezoelectric effect analyses, piezoelectric material with large piezoelectric coefficients and electromechanical coupling coefficients can improve the electromechanical conversion efficiency of PEHs [21]. The piezoelectric ceramic PZT-5H was chosen in this work in consideration of its structural durability and electrical stability. To reduce energy loss and increase service life, researchers have optimized piezoelectric transducers to layered bridge [36], stacked [37], and multilayer cantilever [38] structures. However, these structures have not been widely used due to complex preparation processes or high costs. Therefore, this case study developed a pile-unit-based device and a bridge-unit-based device. Apart from the transducers, piezoelectric devices that can be buried inside pavement included rectifiers, a silicon substrate, a rubber sealing strip, a rigid top plate, a bottom plate, and connecting components (Figure 1). The pile transducer was $20 \mathrm{~mm}$ in diameter and $20 \mathrm{~mm}$ in height with protective gaskets attached on both ends. The bridge transducer consisted of two $2.4 \mathrm{~mm}$ high steel end caps and a $30 \mathrm{~mm} \times 20 \mathrm{~mm} \times 2 \mathrm{~mm}$ piezoelectric ceramic. The steel end cap was optimized with an arc design to avoid structural damage. Since a single transducer generates adverse current under a vehicle load, these transducers were connected to full-bridge rectifiers before being assembled in an array to avoid adversely affecting one another. As shown in Figure 1, sixteen units in parallel connection were installed inside the silicon substrate. The external shell of the piezoelectric device was composed of engineering plastics to meet the technical requirements of high strength, high stiffness, high insulation performance, and corrosion resistance. Based on the size of the tire contact area, and transducer numbers, the piezoelectric devices were determined to be $200 \mathrm{~mm} \times 200 \mathrm{~mm}$. The waterproof design of the package was constructed with a rubber sponge and glass adhesive, and these components were closely assembled using steel bolts at the edge of the plate.

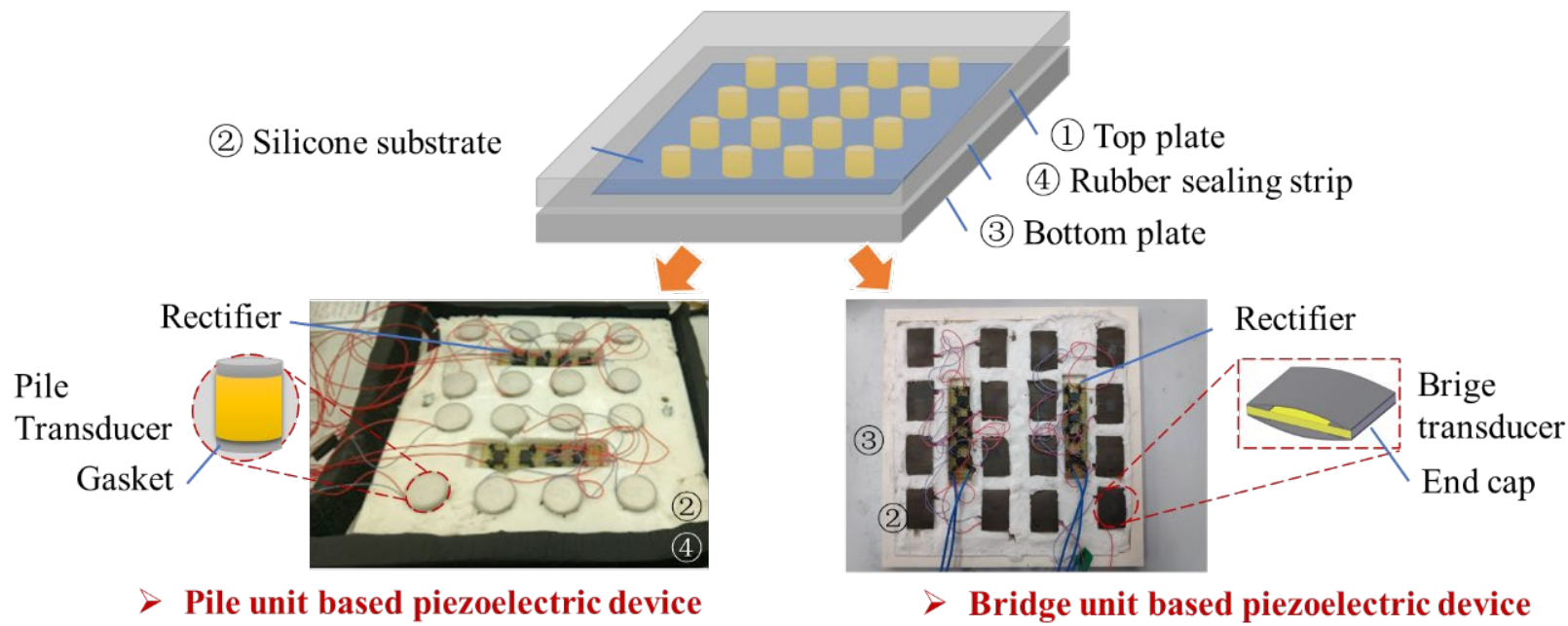

Figure 1. Structures of the PEHs.

\subsection{Test and Evaluation}

Piezoelectric devices for roadway applications must meet the technical requirements of structural durability, electrical stability, and high energy conversion efficiency, while avoiding degrading the pavement performance. Based on the existing literature, this work tested and evaluated the performance of the piezoelectric devices from the three aspects of mechanical performance, electrical performance, and electromechanical coupling performance.

\subsubsection{Mechanical Performance}

The stiffness difference between the device and the pavement can cause both a bonding failure of the device-pavement interface and lead to the uncoordinated deformation of the 
device-pavement composite structure, thus affecting the service performance of both the pavement and the device. Moreover, premature damages in the pavement and piezoelectric devices may appear, shortening the service life and threatening traffic safety [39]. The elastic modulus $E^{\prime}$ of the piezoelectric devices was used to evaluate the mechanical performance, which can be calculated using (1):

$$
E^{\prime}=\frac{F H}{S L}
$$

where $F$ is the vertical load, $L$ is the vertical displacement, $S$ is the surface area of the piezoelectric device, and $H$ is the height of the piezoelectric device.

In this test, an MTS was used to simulate the traffic load. A vertical sinusoidal load was applied at the frequency of $10 \mathrm{~Hz}$ with vertical compressive loads controlled at $0.5 \mathrm{MPa}$, $0.7 \mathrm{MPa}$, and $0.9 \mathrm{MPa}$. The vertical displacement and load were measured simultaneously. Subsequently, the structural modulus of the piezoelectric devices was calculated using (1).

\subsubsection{Electromechanical Coupling Performance}

The electromechanical coupling performance is an important evaluation index to evaluate the energy harvesting efficiency of piezoelectric materials, structures, and devices [18]. When selecting piezoelectric materials, parameters such as the electromechanical coupling coefficient, energy conversion factor, and mechanical quality factor are used to describe the electromechanical conversion performance properties. However, factors such as the material, structure, array, and circuits of piezoelectric devices significantly impact energy loss, as do factors such as the vehicle load, environment, and pavement structure. It is impossible to measure and calculate the energy loss in each process. Therefore, this work adopts the electromechanical conversion coefficient $\eta$ to describe the ratio of the energy output of the device and the work performed by the load. The new evaluation indexes of the energy harvesting efficiency of the piezoelectric devices can be seen in (2) through (4):

$$
\begin{gathered}
Q_{1}=\int_{t_{1}}^{t_{2}} F(t) L d t \\
Q_{2}=\int_{t_{1}}^{t_{2}} \frac{U_{\mathrm{out}}{ }^{2}(t)}{R_{\mathrm{m}}} d t \\
\eta=\frac{Q_{2}}{Q_{1}} \times 100 \%
\end{gathered}
$$

where $Q_{1}$ is the external work, $t$ is the time, $Q_{2}$ is the output energy, $U_{\text {out }}$ is the output voltage, and $R_{\mathrm{m}}$ is the matching impedance.

An MTS, resistors, and electrical properties monitoring equipment were used in this test. The sinusoidal load frequencies were set to $5 \mathrm{~Hz}$ and $10 \mathrm{~Hz}$, and the vertical compressive stresses were $0.5 \mathrm{MPa}, 0.7 \mathrm{MPa}$, and $0.9 \mathrm{MPa}$. The voltage of the piezoelectric devices connected with the optimal load impedance was monitored by a digital oscilloscope.

\subsubsection{Electrical Performance}

The piezoelectric devices convert mechanical energy into electrical energy based on the positive piezoelectric effect of the piezoelectric material. Its piezoelectric equation is shown in (5):

$$
\begin{aligned}
& S=s^{\mathrm{E}} T+d^{\mathrm{t}} E \\
& D=d T+\varepsilon^{\mathrm{T}} E
\end{aligned}
$$

where $S$ is the strain tensor, $s^{\mathrm{E}}$ is the flexibility coefficient tensor under constant electric field, $d$ is the piezoelectric strain constant tensor, $d^{\mathrm{t}}$ is the transposition of $d, E$ is the tensor for the external electric field, $T$ is the stress tensor, $D$ is the electric displacement tensor, and $\varepsilon_{\varepsilon^{\mathrm{T}}}$ is the dielectric constant tensor under a constant stress condition. 
In the non-resonant state, the open-circuit voltage $U_{\mathrm{oc}}$, output voltage $U_{\text {out }}$, and output power $P_{\text {out }}$ collected by the pile unit under the vertical stress $T(t)$ can be deduced from the linear piezoelectric equation, as shown in (6) through (8):

$$
\begin{gathered}
U_{o c}=\frac{Q}{C}=\frac{d_{33} T(t) h}{\varepsilon_{33} T}=g_{33} T(t) h \\
U_{\text {out }}(t)=\frac{U_{o c} R_{L}}{R_{p}+R_{L}}=-g_{33} T(t) h \frac{R_{L}}{R_{p}+R_{L}} \\
P_{\text {out }}(t)=\frac{U_{\text {out }}^{2}}{R_{L}}=\left[g_{33} T(t) h\right]^{2} \frac{R_{L}}{\left(R_{p}+R_{L}\right)^{2}}
\end{gathered}
$$

where $Q$ is the charge, $C$ is the capacitance, $g_{33}$ is the piezoelectric voltage constant, $R_{p}$ is the internal resistance, and $R_{L}$ is the load resistance.

To further investigate the electrical fatigue of the piezoelectric devices under cyclic loads, this work defines the voltage attenuation ratio after 100,000 loadings as the evaluation index of the energy output variation, as shown in (9):

$$
n=\frac{U^{\prime}}{U_{0}} \times 100 \%
$$

where $U_{0}$ and $U^{\prime}$ are the peak voltages before and after the electrical fatigue test, respectively.

To obtain the real electrical properties of the piezoelectric devices under the wheel loads, the piezoelectric devices were buried in a concrete slab with the dimensions of $4 \mathrm{~m} \times 3 \mathrm{~m} \times 0.24 \mathrm{~m}$. The APT device-a one-third scale model mobile load simulator (MMLS3) - was used to simulate the wheel load. The experimental speed was set to $6 \mathrm{~m} / \mathrm{s}$, and the tire pressure was set to $0.7 \mathrm{MPa}$. Eight piezoelectric units on one side were connected in parallel to form a piezoelectric array, and a DPO2024 digital oscilloscope and GENTEK G3100 high-impedance probe were used to monitor the voltage across the load resistors. Figure 2 portrays the experimental setup and electrical performance monitoring equipment.

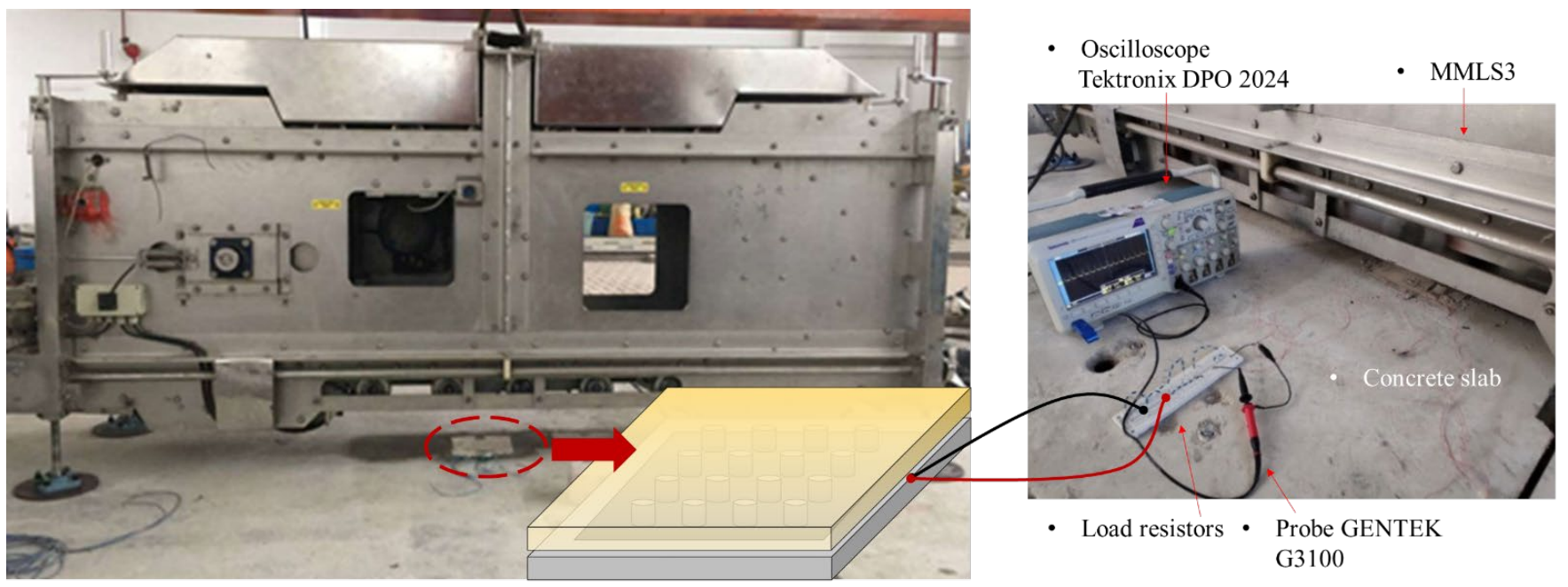

Figure 2. Electrical performance testing equipment.

\section{Results and Discussion}

\subsection{Mechanical Performance}

Figure 3 depicts the elastic modulus of the two piezoelectric devices with compressive stress variations at $10 \mathrm{~Hz}$. The elastic modulus of the pile-unit-based piezoelectric device gradually increased with the stress variations. Under the same stress magnitude, the elastic modulus of the pile device was significantly higher than that of the bridge device. When 
the stress magnitude was smaller than $0.5 \mathrm{MPa}$, the deformation of the device was mainly contributed to by the silicone substrate and rubber sealing strips. As the stress magnitude increased, the deformation was contributed to by the piezoelectric units and external package shells. In addition, the elastic modulus of the bridge device had a small decrease when the load increased to $0.7 \mathrm{MPa}$. This change may have been due to the deformation of the steel end cap of the bridge transducer under a high-stress state. Although the modulus of the device's fabrication material exceeded $6000 \mathrm{MPa}$, the elastic modulus of the device was still significantly lower than that of the pavement structure. The low elastic modulus of the device was mainly influenced by factors such as the transducer array, flexible filling materials, and packaging fabrication errors. To avoid attenuation in the service performance and fatigue life of both the pavement and device, several elastic modulus improvement solutions were proposed:

1. Use a metal top plate instead of a plastic top plate to increase the stiffness of the shell, thus reducing the uneven deformation between the device and pavement;

2. Apply prestress to the piezoelectric device using bolts to produce sufficient compressive deformation before the load is applied;

3. Use a high-precision lathe and three-dimensional printing technology to decrease the fabrication errors in the preparation process.

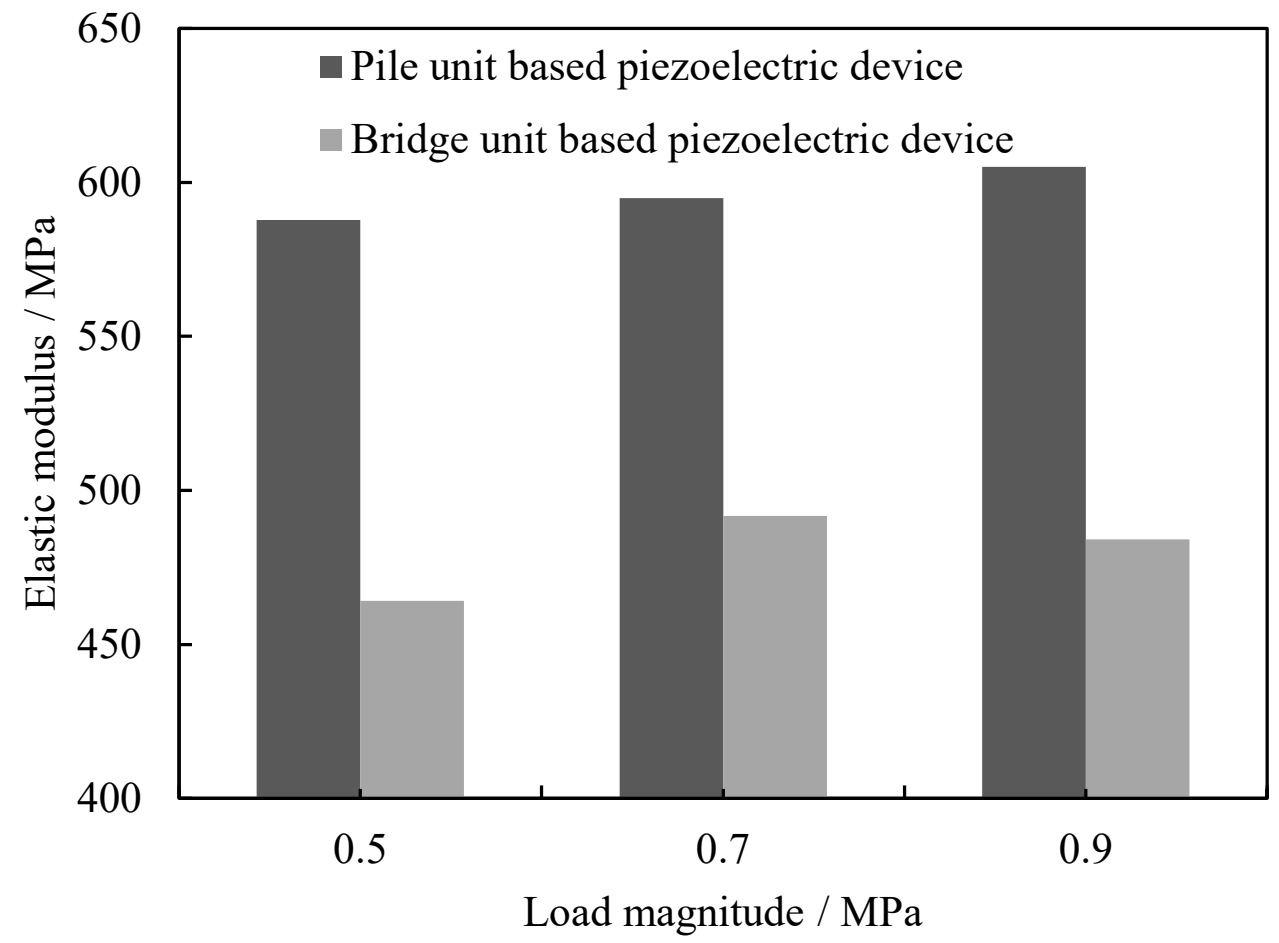

Figure 3. Elastic modulus of the piezoelectric device $(10 \mathrm{~Hz})$.

\subsection{Electromechanical Conversion Performance}

Figure 4 depicts the electromechanical conversion coefficients under different load conditions. In Figure $4 \mathrm{a}$, the electromechanical conversion coefficients of the pile-unit-based piezoelectric device were stable at around $8.2 \%$, which demonstrated little sensitivity to vertical compressive stress and frequency variations. Moreover, they were lower than the electromechanical coupling parameters of the piezoelectric materials. This result may be because the electromechanical conversion coefficient $\eta$ was a comprehensive evaluation index of the energy harvesting efficiency of the piezoelectric device, which combined multiple elements, such as the electromechanical coupling coefficient, energy conversion factor, mechanical quality factor, mechanical structure loss, and circuit loss. Figure $4 \mathrm{~b}$ shows that the electromechanical conversion coefficients of the bridge structure were around $7.1 \%$ and did not change significantly with the load and frequency variations. However, the 
electromechanical conversion efficiency of the bridge structure was slightly smaller than that of the pile structure. This inequality was related to the mechanical loss generated by the end-cap deformation and preparation accuracy of the bridge-unit-based device.

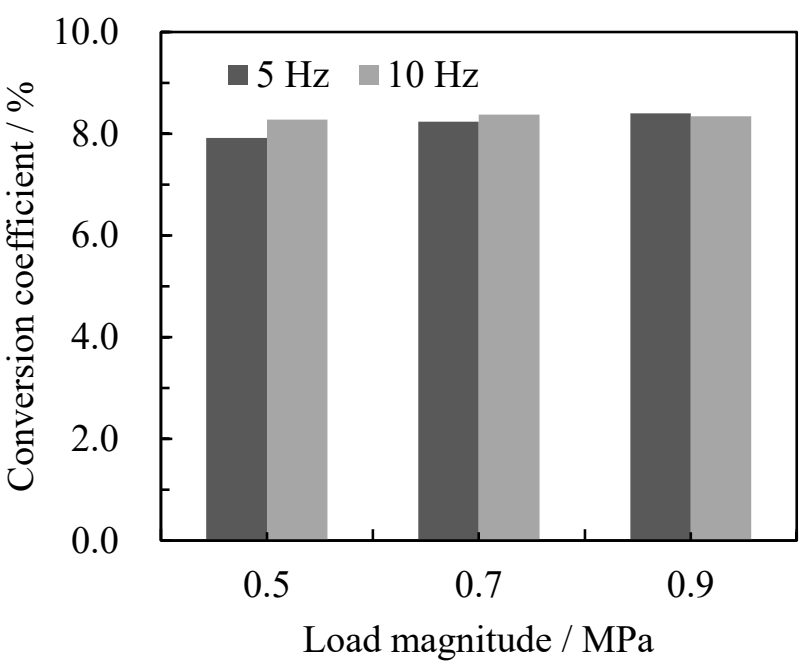

(a)

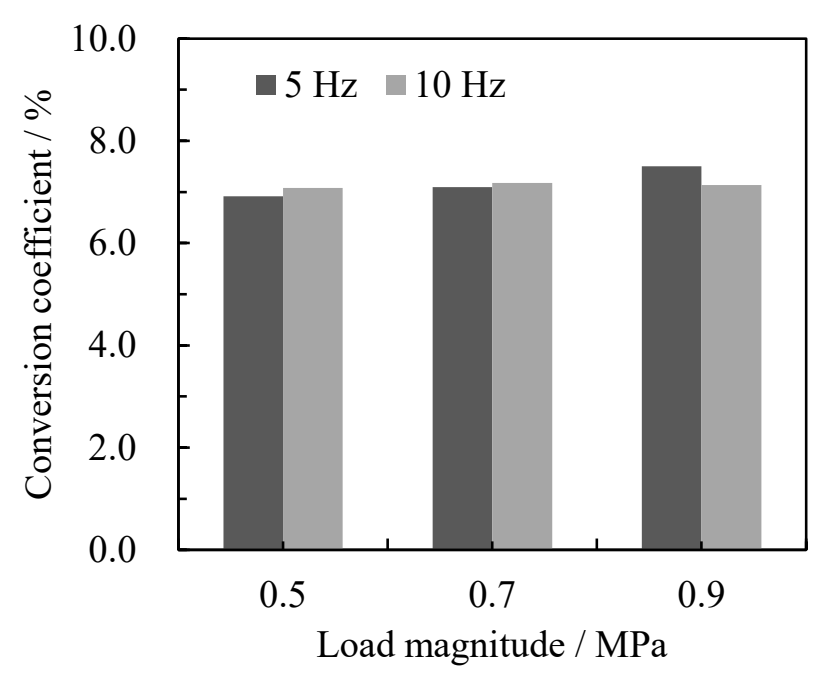

(b)

Figure 4. Electromechanical conversion coefficient: (a) pile-unit-based piezoelectric device and (b) bridge-unit-based piezoelectric device.

\subsection{Electrical Performance}

\subsubsection{Electrical Output}

The voltage properties of the two proposed devices were measured using a DPO2024 oscilloscope and GENTEK G3100 impedance probe under different load resistors. In this full-scale test, load resistors varying from $0 \mathrm{M} \Omega$ to $50 \mathrm{M} \Omega$ were used to ascertain the maximum output energy with the matched resistance. Figure 5 contains the profiles of the voltage waveform in the half pile-unit-based array and half bridge-unit-based array under the matched load resistance. The output power was calculated by integrating the response time and the measured voltage using (10). Figure 5a illustrates that the output voltage of the half pile-unit-based array was approximately $300 \mathrm{~V}$ and the output power generated was $1.7 \mathrm{~mW}$ with an optimal resistance of $10.0 \mathrm{M} \Omega$. In addition, under a matched load resistance of $750 \mathrm{k} \Omega$, the total output power of the half bridge-unit-based array was $1.3 \mathrm{~mW}$ with a voltage smaller than $100 \mathrm{~V}$. Furthermore, the energy output of the bridge structure was lower than that of the pile structure due to the fast decay of the voltage signal. Considering the symmetrical arrangement of the array inside, the total output power of the devices was $3.4 \mathrm{~mW}$ and $2.6 \mathrm{~mW}$, the values of which meet the low-power sensor supply requirements $[8,29,30]$.

$$
P_{L}=\frac{W}{t}=\frac{\int_{0}^{\Delta t} \frac{U_{L}^{2}}{R_{L}} d(t)}{\Delta t}
$$

where $P_{L}$ is the output power of the circuit, $U_{L}$ is the measured output voltage, and $\Delta t$ is the accumulated time of the output voltage waveform.

\subsubsection{Electrical Fatigue}

The fatigue test was conducted using an MMLS3 in the full-scale test, and a DPO2024 digital oscilloscope was used to monitor the voltage signals of the devices connected with the matched load resistors. Figure 6 contains the output voltage variation curve of the pile device under a wheel load of $6 \mathrm{~m} / \mathrm{s}$ and $0.7 \mathrm{MPa}$. The samples were taken every 10,000 loadings, and 10 measurements were recorded to reduce the experimental error. During the electrical fatigue tests, the mean value of the peak voltage was maintained at approximately $360 \mathrm{~V}$, and no obvious electrical decay was found. Accounting for the effects 
of errors in wheel loads and the environmental noise, the electrical performance of the pile device was free of degradation.

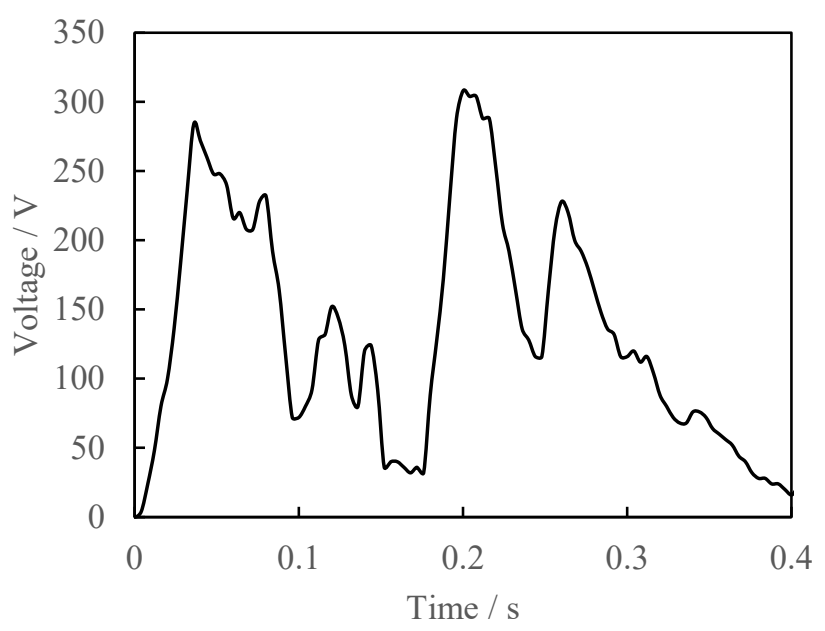

(a)

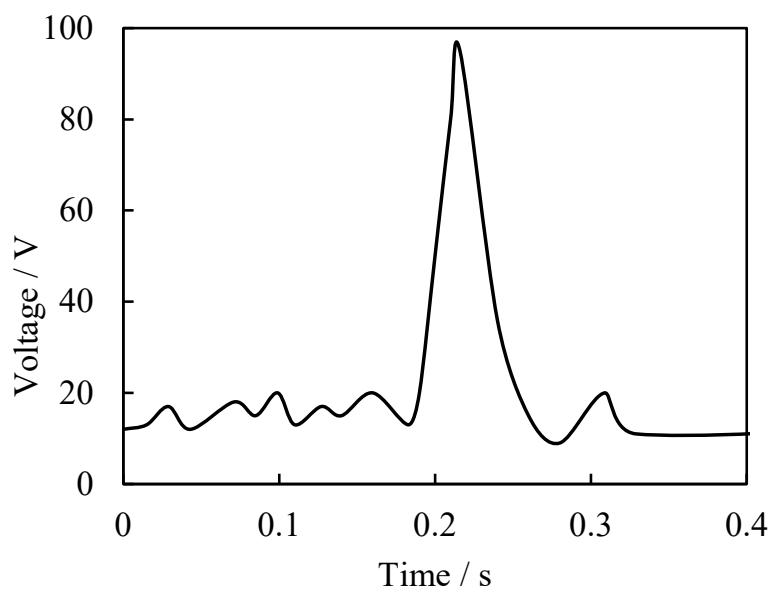

(b)

Figure 5. Voltage waveform: (a) half pile-unit-based array and (b) half bridge-unit-based array.

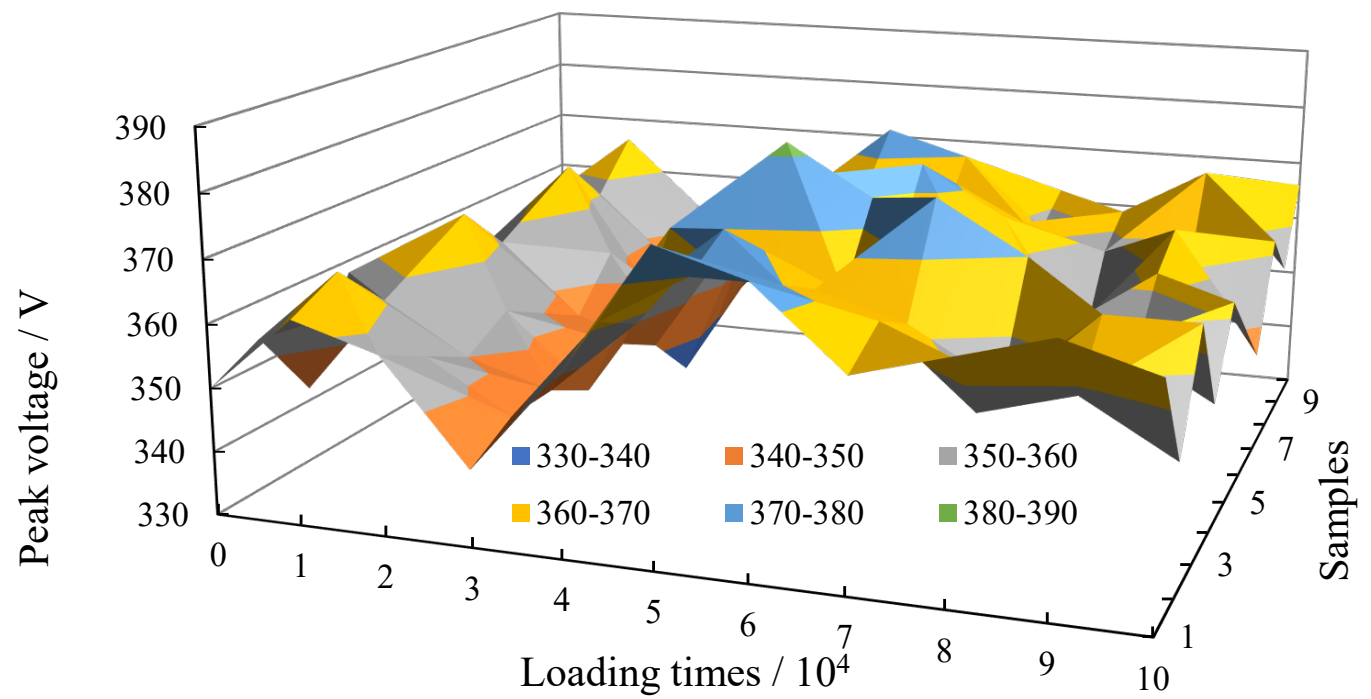

Figure 6. Electric property of the pile-unit-based piezoelectric device.

Table 1 lists the electrical fatigue properties of the pile and bridge structures. The mean value of the peak voltage of the pile structure device was stable at around $350 \mathrm{~V}$ after the fatigue test. Although the coefficient of variation of the peak voltage increased from $0.97 \%$ to $2.20 \%$, no significant electrical attenuation appeared. An integral calculation demonstrates that the output power of the device increased from $3.4 \mathrm{~mW}$ to $3.6 \mathrm{~mW}$ after the fatigue test. However, the peak voltage and output power of the bridge structure decreased significantly after the fatigue test. In particular, the voltage decreased by $39 \%$ and the output power of the device decreased from $2.6 \mathrm{~mW}$ to $1.4 \mathrm{~mW}$. The test revealed cumulative deformation and fatigue damage in the bridge unit under the cyclic load, which deteriorated the stress amplification effect and energy harvesting efficiency. The results indicate that the pile piezoelectric device exhibited an excellent electrical fatigue performance. 
Table 1. Electric fatigue testing of the piezoelectric devices.

\begin{tabular}{ccccccc}
\hline \multirow{2}{*}{ Device } & \multicolumn{3}{c}{ Voltage $(\mathrm{V})$} & & \multicolumn{2}{c}{ Power (mW) } \\
\cline { 2 - 7 } & $\begin{array}{c}\text { Mean Value } \\
\text { before Test }\end{array}$ & $\begin{array}{c}\text { Mean Value } \\
\text { after Test }\end{array}$ & Attenuation & Before & After & Attenuation \\
\hline Pile structure & 349 & 347 & No Sig. & 3.4 & 3.6 & No Sig. \\
Bridge structure & 95 & 58 & $-39 \%$ & 2.6 & 1.4 & $-46 \%$ \\
\hline
\end{tabular}

\section{Conclusions}

This work assessed and compared the performance of a pile-unit-based and bridgeunit-based piezoelectric device using a multiscale test and evaluation method. Both the pile-structure device and the bridge-structure device could be used for pavement energy harvesting, but the two devices displayed significant differences in their electrical performance, mechanical performance, and electromechanical coupling performance. Several conclusions can be drawn:

1. The elastic modulus of the pile structure device was higher than that of the bridge structure device, but the modulus of both devices was significantly lower than that of the pavement structure. Further optimization of the package and fabrication is needed to improve the modulus of the piezoelectric device;

2. The electromechanical conversion coefficient of the pile structure device was superior to that of the bridge structure device. Both structures' coefficients were smaller than $10 \%$ and not sensitive to the load characteristics;

3. Both of the piezoelectric devices achieved $\mathrm{mW}$ power under the wheel load simulated by the MMLS3 and could be utilized to supply low-power sensors;

4. The material stiffness, electromechanical conversion efficiency, and electrical performance of the pile structure device are superior to those of the bridge structure device, which has better application prospects in the field of pavement energy harvesting.

The evaluation indexes and multiscale tests proposed in this work can provide a reference for further investigations of PEH technology.

Author Contributions: Conceptualization, H.Z. and C.L.; methodology, C.L.; formal analysis, C.L. and S.L.; investigation, C.L.; data curation, C.L.; writing-original draft preparation, C.L. and Y.T.; writing-review and editing, C.L. and Y.T.; funding acquisition, H.Z. All authors have read and agreed to the published version of the manuscript.

Funding: This research was funded by the National Natural Science Fund of China (No. 51778477), the National Key R\&D Program of China (No. 2018YFB1600300) and the China Scholarship Council (No. 202006260165).

Institutional Review Board Statement: Not applicable.

Informed Consent Statement: Not applicable.

Data Availability Statement: Not applicable.

Conflicts of Interest: The authors declare no conflict of interest.

\section{References}

1. Wang, J.; Xiao, F.; Zhao, H. Thermoelectric, piezoelectric and photovoltaic harvesting technologies for pavement engineering. Renew. Sustain. Energy Rev. 2021, 151, 111522. [CrossRef]

2. Pei, J.; Zhou, B.; Lyu, L. E-Road: The largest energy supply of the future? Appl. Energy 2019, 241, 174-183. [CrossRef]

3. Gholikhani, M.; Roshani, H.; Dessouky, S.; Papagiannakis, A.T. A critical review of roadway energy harvesting technologies. Appl. Energy 2020, 261, 114388. [CrossRef]

4. Calautit, K.; Nasir, D.S.N.M.; Hughes, B.R. Low power energy harvesting systems: State of the art and future challenges. Renew. Sustain. Energy Rev. 2021, 147, 111230. [CrossRef]

5. Karan, S.K.; Maiti, S.; Lee, J.H.; Mishra, Y.K.; Khatua, B.B.; Kim, J.K. Recent Advances in Self-Powered Tribo-/Piezoelectric Energy Harvesters: All-In-One Package for Future Smart Technologies. Adv. Funct. Mater. 2020, 30, 2004446. [CrossRef]

6. Sun, L.; Zhao, H.; Tu, H.; Tian, Y. The Smart Road: Practice and Concept. Engineering 2018, 4, 436-437. [CrossRef] 
7. Xiao, J.; Zou, X.; Xu, W. ePave: A Self-Powered Wireless Sensor for Smart and Autonomous Pavement. Sensors 2017, $17,2207$. [CrossRef]

8. Ye, Z.; Xiong, H.; Wang, L. Collecting comprehensive traffic information using pavement vibration monitoring data. Comput.-Aided Civ. Infrastruct. Eng. 2019, 35, 134-149. [CrossRef]

9. You, Y.-M.; Liao, W.-Q.; Zhao, D.; Ye, H.-Y.; Zhang, Y.; Zhou, Q.; Niu, X.; Wang, J.; Li, P.-F.; Fu, D.-W.; et al. An organic-inorganic perovskite ferroelectric with large piezoelectric response. Science 2017, 357, 306-309. [CrossRef]

10. Bhunia, S.; Chandel, S.; Karan, S.K.; Dey, S.; Tiwari, A.; Das, S.; Kumar, N.; Chowdhury, R.; Mondal, S.; Ghosh, I.; et al. Autonomous self-repair in piezoelectric molecular crystals. Science 2021, 373, 321-327. [CrossRef]

11. Li, C.; Yang, F.; Liu, P.; Fu, C.; Liu, Q.; Zhao, H.; Lin, P. Development and Piezoelectric Properties of a Stack Units-Based Piezoelectric Device for Roadway Application. Sensors 2021, 21, 7708. [CrossRef]

12. Zhao, Q.; Wang, L.; Zhao, K.; Yang, H. Development of a Novel Piezoelectric Sensing System for Pavement Dynamic Load Identification. Sensors 2019, 19, 4668. [CrossRef]

13. Yuan, H.; Wang, S.; Wang, C.; Song, Z.; Li, Y. Design of piezoelectric device compatible with pavement considering traffic: Simulation, laboratory and on-site. Appl. Energy 2022, 306, 118153. [CrossRef]

14. Hong, S.D.; Kim, K.-B.; Hwang, W.; Song, Y.S.; Cho, J.Y.; Jeong, S.Y.; Ahn, J.H.; Kim, G.-H.; Cheong, H.; Sung, T.H. Enhanced energy-generation performance of a landfilled road-capable piezoelectric harvester to scavenge energy from passing vehicles. Energy Convers. Manag. 2020, 215, 112900. [CrossRef]

15. Ahmad, S.; Abdul Mujeebu, M.; Farooqi, M.A. Energy harvesting from pavements and roadways: A comprehensive review of technologies, materials, and challenges. Int. J. Energy Res. 2019, 43, 1974-2015. [CrossRef]

16. Zhao, H.; Tao, Y.; Niu, Y.; Ling, J. Harvesting energy from asphalt pavement by piezoelectric generator. J. Wuhan Univ. Technol. Sci. Ed. 2014, 29, 933-937. [CrossRef]

17. Zhao, H.; Yu, J.; Ling, J. Finite element analysis of Cymbal piezoelectric transducers for harvesting energy from asphalt pavement. J. Ceram. Soc. Jpn. 2010, 118, 909-915. [CrossRef]

18. Zhao, H.; Ling, J.; Yu, J. A comparative analysis of piezoelectric transducers for harvesting energy from asphalt pavement J. Ceram. Soc. Jpn. 2012, 120, 317-323. [CrossRef]

19. Jasim, A.; Wang, H.; Yesner, G.; Safari, A.; Maher, A. Optimized design of layered bridge transducer for piezoelectric energy harvesting from roadway. Energy 2017, 141, 1133-1145. [CrossRef]

20. Goh, P.H.; Li, M.-J.; Tsou, N.-T. The design and analysis for low-frequency piezoelectric cymbal transducers. Ceram. Int. 2017, 43, S49-S54. [CrossRef]

21. Li, C.; Ma, H.Z.L.; Zeng, M.; Liu, P. Design and performance analysis of stacked piezoelectric units for pavement application. J. Cent. South Univ. 2021, 52, 2170-2178.

22. Kim, J.; Lee, T.H.; Song, Y.; Sung, T.H. Robust design optimization of fixed-fixed beam piezoelectric energy harvester considering manufacturing uncertainties. Sens. Actuators A Phys. 2017, 260, 236-246. [CrossRef]

23. Wang, C.; Song, Z.; Gao, Z.; Yu, G.; Wang, S. Preparation and performance research of stacked piezoelectric energy-harvesting units for pavements. Energy Build. 2019, 183, 581-591. [CrossRef]

24. Wang, C.; Wang, S.; Gao, Z.; Wang, X. Applicability evaluation of embedded piezoelectric energy harvester applied in pavement structure. Res. Appl. Energy 2019, 251, 113383. [CrossRef]

25. Yang, H.; Guo, M.; Wang, L.; Hou, Y.; Zhao, Q.; Cao, D.; Zhou, B.; Wang, D. Investigation on the factors influencing the performance of piezoelectric energy harvester. Road Mater. Pavement Des. 2017, 18, 180-189. [CrossRef]

26. Yang, H.; Wang, L.; Hou, Y.; Guo, M.; Ye, Z.; Tong, X.; Wang, D. Development in Stacked-Array-Type Piezoelectric Energy Harvester in Asphalt Pavement. J. Mater. Civ. Eng. 2017, 29, 04017224. [CrossRef]

27. Zhao, H.; Qin, L.; Ling, J. Synergistic performance of piezoelectric transducers and asphalt pavement. Int. J. Pavement Res. Technol. 2018, 11, 381-387. [CrossRef]

28. Cao, Y.; Sha, A.; Liu, Z.; Luan, B.; Li, J.; Jiang, W. Electric energy output model of a piezoelectric transducer for pavement application under vehicle load excitation. Energy 2020, 211, 118595. [CrossRef]

29. Cao, Y.; Sha, A.; Liu, Z.; Li, J.; Jiang, W. Energy output of piezoelectric transducers and pavements under simulated traffic load. J. Clean. Prod. 2021, 279, 123508. [CrossRef]

30. Tong, X.; Song, S.; Wang, L.; Yang, H. A preliminary research on wireless cantilever beam vibration sensor in bridge health monitoring. Front. Struct. Civ. Eng. 2017, 12, 207-214. [CrossRef]

31. Wang, S.; Wang, C.; Gao, Z.; Cao, H. Design and performance of a cantilever piezoelectric power generation device for real-time road safety warnings. Appl. Energy 2020, 276, 115512. [CrossRef]

32. Roshani, H.; Dessouky, S.; Papagiannakis, A.T.; Montoya, A. Experimental and finite element assessment of three energy harvesting prototypes for roadways. Innov. Infrastruct. Solutions 2017, 2, 7. [CrossRef]

33. Liu, P.; Zhao, Q.; Yang, H.; Wang, D.; Oeser, M.; Wang, L.; Tan, Y. Numerical Study on Influence of Piezoelectric Energy Harvester on Asphalt Pavement Structural Responses. J. Mater. Civ. Eng. 2019, 31, 04019008. [CrossRef]

34. Yang, H.; Wang, L.; Zhou, B.; Wei, Y.; Zhao, Q. A preliminary study on the highway piezoelectric power supply system. Int. J. Pavement Res. Technol. 2018, 11, 168-175. [CrossRef]

35. Wang, C.; Wang, S.; Gao, Z.; Song, Z. Effect evaluation of road piezoelectric micro-energy collection-storage system based on laboratory and on-site tests. Appl. Energy 2021, 287, 116581. [CrossRef] 
36. Jasim, A.; Yesner, G.; Wang, H.; Safari, A.; Maher, A.; Basily, B. Laboratory testing and numerical simulation of piezoelectric energy harvester for roadway applications. Appl. Energy 2018, 224, 438-447. [CrossRef]

37. Wang, C.; Yu, G.; Cao, H.; Wang, S.; Li, Y. Structure simulation optimization and test verification of piezoelectric energy harvester device for road. Sensors Actuators A Phys. 2020, 315, 112322. [CrossRef]

38. Wang, S.; Wang, C.; Yu, G.; Gao, Z. Development and performance of a piezoelectric energy conversion structure applied in pavement. Energy Convers. Manag. 2020, 207, 112571. [CrossRef]

39. Chen, F.; Coronado, C.F.; Balieu, R.; Kringos, N. Structural performance of electrified roads: A computational analysis. J. Clean. Prod. 2018, 195, 1338-1349. [CrossRef] 